УДК 620.172 .2

\title{
ЗАКОНОМЕРНОСТИ РАЗРУШЕНИЯ МАТЕРИАЛА УДАРНИКА ПРИ ПОВТОРЯЮЩИХСЯ ЕДИНИЧНЫХ УДАРАХ
}

\author{
В.И.БОЛОБОВ, ЛЕ ТХАНЬ БИНЬ \\ Санкт-Петербургский горный университет, Санкт-Петербург, Россия
}

\begin{abstract}
Представлены методика и результаты экспериментов по исследованию закономерностей процесса изнашивания конусообразного острия свободно падающего ударника, изготовленного из сталей $38 \mathrm{XM}$, У8, $\mathrm{X} 12 \mathrm{MФ,} \mathrm{подвергнутого} \mathrm{типовой} \mathrm{термической} \mathrm{обработке} \mathrm{и} \mathrm{дополнительно} \mathrm{обработанного} \mathrm{холодом,} \mathrm{при} \mathrm{нане-}$ сении им многократных (до 10000) единичных ударов по граниту в условиях, приближающихся к условиям работы пики гидромолота. Для объяснения процессов использованы значения напряжений $\sigma_{\kappa}$, возникающих на площадке контакта ударника и породы, рассчитанные с использованием разработанной математической модели. Установлено, что процесс изнашивания ударника при многократном единичном ударе протекает в три стадии, разделяющиеся критическими значениями $\sigma_{\kappa}^{*}, \sigma_{\kappa}^{* *}$, которые соответствуют прочностным характеристикам материала ударника, демонстрируемым в данных динамических условиях.

При малом числе ударов $\left(n \leq n^{*}\right)$ и малых размерах площадки притупления (стадия I взаимодействия) значения $\sigma_{\kappa}$ превышают $\sigma_{\kappa}^{*}$ стали и она на площадке контакта подвергается локальному разрушению, что регистрируется в виде значительной убыли массы ударника; при $n^{*}<n \leq n^{* *}$ (стадия II) возникающих напряжений не хватает для разрушения материала, но оказывается достаточно для его пластической деформации, сопровождаемой перемещением металла с центральной части площадки контакта на периферийную и разрушением части деформированного металла породой; при $n>n^{* *}$ (стадия III) возникающие $\sigma_{\mathrm{K}}$ не достигают уровня $\sigma_{\kappa}^{* *}$ и убыль массы ударника определяется стойкостью использованной стали к истиранию продуктами разрушения породы, вытесняемыми ударником из лунки. Обработка ударников из всех испытанных сталей холодом приводит к повышению их износостойкости; суммарная глубина лунок, выколотых обработанным холодом ударником из стали Х12МФ к моменту прекращения внедрения породу, в четыре раза превышает аналогичный показатель для ударника из стали $38 \mathrm{XM}$, подвергнутого типовой термической обработке.

Ключевые слова: многократный единичный удар; конусообразный стальной ударник; обработка холодом; абразивный износ; изнашивание металла
\end{abstract}

Как цитировать эту статью: Болобов В.И. Закономерности разрушения материала ударника при повторяющихся единичных ударах / В.И.Болобов, Ле Тхань Бинь // Записки Горного института. 2018. Т. 233. C. 525-533. DOI: 10.31897/PMI.2018.5.525

Введение. Машины ударного разрушения отбойкой и скалыванием широко используются при проведении горных выработок, для демонтажа огнеупорной футеровки при ремонте доменных и мартеновских печей, при разработке мерзлых и скальных грунтов, вскрытии дорожных покрытий, разрушении бетонных, железобетонных и кирпичных конструкций и пр. [7]. В качестве рабочего инструмента в этих машинах обычно используются пики цилиндрической формы в виде конуса или клина, заточенные под углом, как правило, от 30 до 40 [5]. Процесс разрушения такими машинами начинается с внедрения инструмента в массив, имеющий достаточно близкие друг к другу свободные поверхности, на такую глубину, чтобы возникающие вследствие внедрения растягивающие и сдвиговые напряжения оторвали от массива кусок необходимых размеров. Работоспособность машины определяется ее способностью внедрить ударный инструмент на заданную глубину, а показателем производительности является скорость внедрения [5].

По мере эксплуатации инструмента из-за ударно-абразивного изнашивания его материала размеры площадки притупления, имеющейся в заостренной части пики, возрастают. Это приводит к увеличению площади контакта инструмента с породой при ударе со снижением интенсивности ударного разрушения. В результате, начиная с некоторого момента, процесс внедрения пики в породу практически прекращается и для его возобновления требуется замена или перезаточка пики. Например, как показывает опыт работы гидромолота DAEMO B180, этот момент для данной машины наступает при изнашивании заостренной части пики примерно на 50 \%, вследствие чего пики хватает на 4-5 перезаточек. С учетом того, что замена массивной пики и ее перезаточка являются весьма трудоемкими процессами, разработка способов, повышающих стойкость материалов пик гидромолотов к ударно-абразивному изнашиванию и, как следствие, время эксплуатации пик до перезаточки, является актуальной задачей. 
Вопросам разрушения породы ударным инструментом и, в частности, гидравлическими молотами посвящено значительное количество исследований. На основании законов механики и классической теории Герца разработаны классическая и волновая теории удара, связывающие энергию, силу и время взаимодействия ударника и разрушаемого материала с глубиной внедрения ударника в породу. Вопросы, связанные с механизмом изнашивания материала ударника и влиянием на производительность гидромолотов величины площадки притупления его острия, изменяющейся во времени в зависимости от износостойкости материала, изучены недостаточно.

В настоящей работе в условиях, приближающихся к условиям работы пик машин ударного разрушения отбойкой и скалыванием, исследованы закономерности процесса изнашивания материала свободно падающего ударника при нанесении им единичных ударов по породе.

Методика эксперимента. Объектом исследования являлись ударники длиной $L=25$ мм с цилиндрической частью $\left(D=6 \mathrm{mм}, l_{1}=13,8\right.$ мм) и конусообразным заострением с углом при вершине $\beta=30^{\circ}$ на длине $l_{2}=11,2$ мм, изготовленные из сталей $38 \mathrm{XM}, \mathrm{У} 8, \mathrm{X} 12 \mathrm{M}$, как материалов пик гидромолотов, отличающиеся прочностью и износостойкостью. Часть сталей подвергали типовой термической обработке (ТТО) - закалке с 800-1000 ${ }^{\circ} \mathrm{C}$ в масле и отпуску при $200{ }^{\circ} \mathrm{C}$, практикуемой на заводах-изготовителях пик, другую - дополнительной обработке [4] холодом (выдержке при $-75^{\circ} \mathrm{C}$ в течение 5 ч) как операции, широко применяемой для улучшения износостойкости инструментальных сталей $[8,10,11,13]$. С использованием универсального твердомеpa Zwick/Roell ZHU определяли твердость материалов ударника, достигнутую в результате термических обработок.

Испытания проводили на установке (рис.1) конструкции, близкой к описанной в [2].

Ударник 2, изготовленный из стали одной из указанных марок, после взвешивания на аналитических весах $( \pm 0,0001$ г) закрепляли в вертикальном положении в массивном бойке 3 $(M=2,8$ кг). Под ударником размещали фрагмент породы 1 гранита крепостью 6,2 по шкале М.М.Протодьяконова с агрегатной твердостью $\sim 450 \mathrm{HV}$ и твердостью составляющих его минералов до $1200 \mathrm{HV}$ (для кварца), превышающей твердость использованных материалов ударника.

При падении бойка с ударником с определенной высоты $(H=42$ мм) осуществляли серию ударов $n$ острием ударника в различные точки поверхности фрагмента, каждый удар в другую точку. Кинетическая энергия $A_{0}$ и предударная скорость $v_{0}$ бойка с ударником, рассчитанные из величин $M$ и $H$, составляли 1,16 Дж и $0,91 \mathrm{~m} / \mathrm{c}$. После каждого удара ударник подвергали повторному взвешиванию и замеру $L$ (точность замера $\pm 0,01$ мм) с определением убыли массы $\Delta m$ и длины $\Delta l$ его острия, по $\Delta l$ с учетом $\beta$ рассчитывали диаметр $d$, образовавшейся площадки притупления. При числе ударов свыше 40 установление $\Delta m$ и $\Delta l$ производили через интервал $n$ (от 10 до 100) и рассчитывали как частное от деления суммарной величины функций за этот интервал на число ударов в интервале. Анализировали вид лунок выкола в породе с замером их глубины $h$

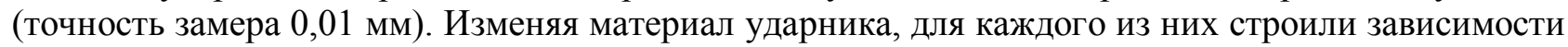
$\Delta l, d, h$ от числа ударов $n$.
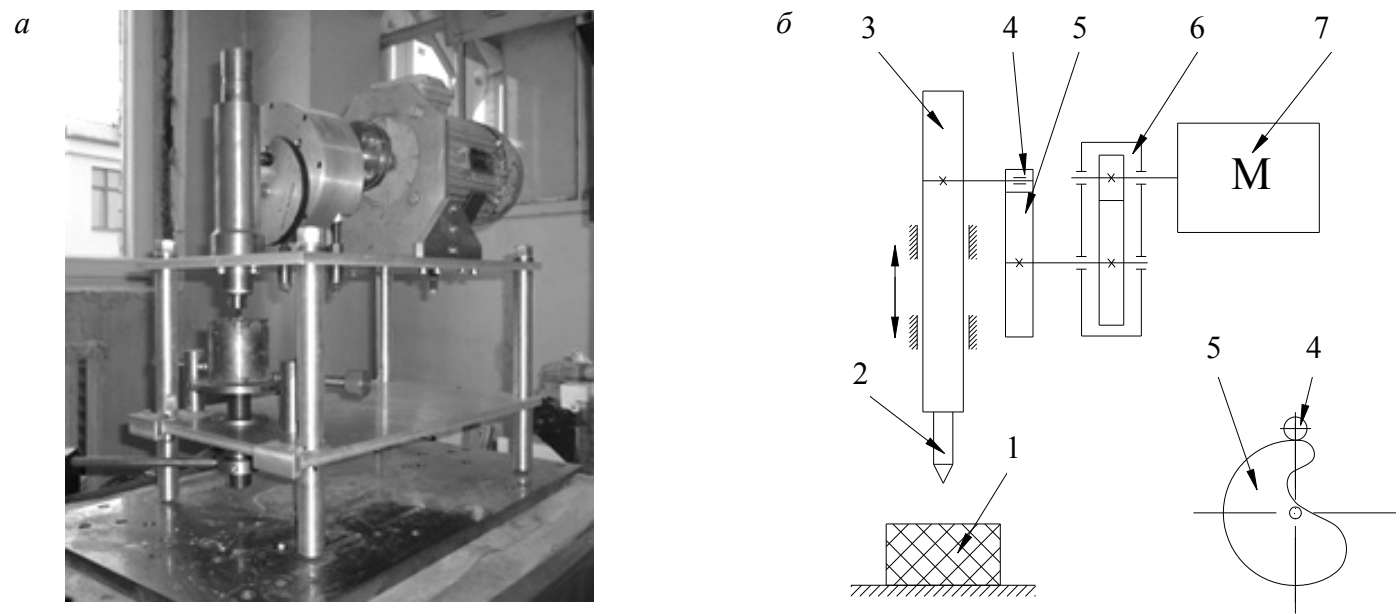

Рис.1. Установка для изучения процесса ударного разрушения горной породы и материала ударника (a) и ее принципиальная схема (б)

1 - фрагмент породы; 2 - ударник; 3 - боек; 4 - ролик; 5 - кулачок; 6 - редуктор; 7 - электродвигатель 
Результаты эксперимента. Как показали наблюдения, процесс удара о гранит сопровождается незначительным (на несколько миллиметров) отскоком ударника. Результатом первого удара является появление на заостренной части ударника кругообразной площадки притупления, диаметр $d$ которой возрастает по мере увеличения числа ударов.

Разрушение гранита характеризуется вылетом из зоны разрушения частичек и пылеобразных фрагментов с образованием лунок выкола формы, близкой к конфигурации внедряющейся части ударника большего диаметра. На дне лунок обнаруживается уплотненное ядро порошкообразных продуктов разрушения, отличающееся цветом (белым) от остальной части породы.

Установлено, что с увеличением числа ударов величины $\Delta l$ и $h$ монотонно убывают (рис.2). Причем, кривые $\Delta l=f(n)$ для анализируемых сталей расположены на графике относительно друг друга в последовательности, обратной расположению кривых $h=f(n)$ для этих же материалов.

Типичный вид полученных зависимостей $\Delta m=f(n)$ представлен на рис.3. Как можно заключить из вида кривых на рис.3, процесс убыли массы ударника $\Delta m$ в зависимости от числа ударов $n$ для всех анализируемых материалов характеризуется тремя стадиями. На первой (стадия I), включающей несколько первых ударов до некоторого критического, различающегося для каждой стали, числа ударов $n^{*}=8-10$, величина $\Delta m$ исчисляется десятыми миллиграммами и снижается с каждым последующим ударом с заметной скоростью (0,3-0,4 мг/удар). На стадии II, начинающейся при $n \geq n^{*}$ и продолжающейся до второго критического значения $n^{* *}=3600-5400$, величина $\Delta m$ составляет только несколько сотых миллиграмма, а скорость ее снижения с ростом $n$ резко замедляется. На стадии III при $n>n^{* *}$, продолжающейся до конца серии опытов, убыль массы $\Delta m$ становится независящей от числа ударов. Это значение $\Delta m$, определенное для каждой стали, принимали за скорость ударно-абразивного изнашивания $K$ материала на установившейся стадии процесса изнашивания, а величину I, обратную $K$ - за ударно-абразивную износостойкость этого материала ударника.

Для объяснения процессов, происходящих на каждой стадии изнашивания ударника, использовали данные о величине напряжений, возникающих на площадке контакта ударника и породы, рассчитанных с использованием разработанной математической модели.
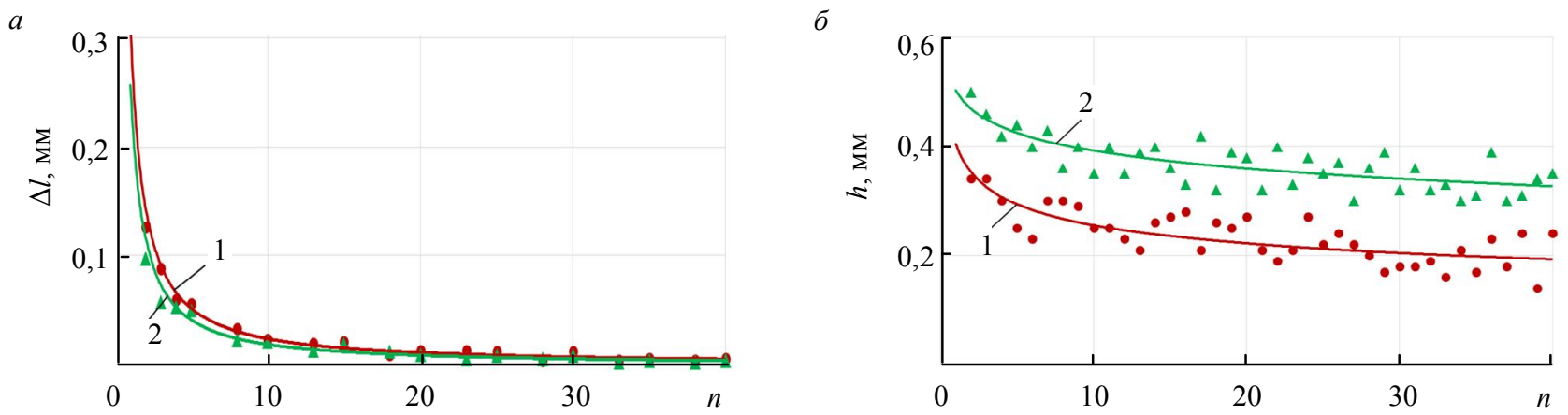

Рис.2. Зависимость убыли длины ударника $\Delta l(a)$ и глубины лунки $h(б)$ от числа ударов $n$ для различных материалов ударника 1 - сталь $38 \mathrm{XM;} 2$ - сталь Х12М Ф (здесь и далее индекс $x$ указывает на обработку стали холодом)
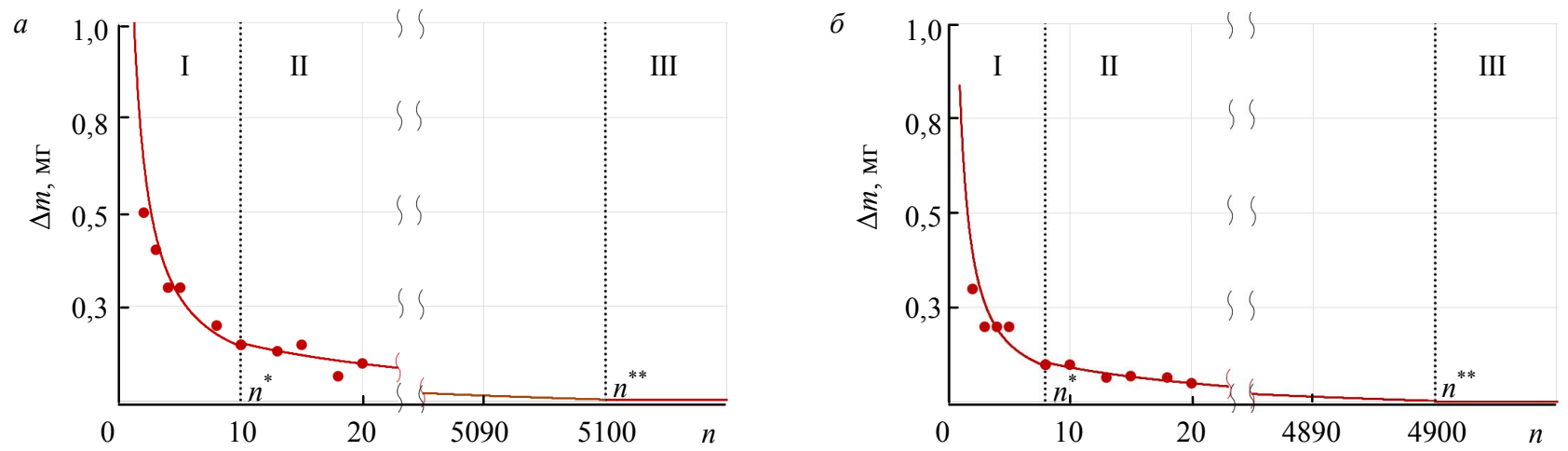

Рис.3. Зависимость убыли массы $\Delta m$ ударника из сталей $38 \mathrm{XM}(a)$ и $\mathrm{X} 12 \mathrm{M} \Phi_{x}($ б) от числа ударов $n$ 
Математическая модель процесса ударного разрушения породы в условиях эксперимента. При разработке модели исходили из того, что ударник вместе с бойком представляет собой конструкцию сравнительно небольшой длины $\left(L_{\Sigma}=340\right.$ мм). Считали, что влиянием волновых процессов на параметры удара можно пренебречь и процесс взаимодействия ударника и разрушаемого материала может быть описан уравнениями двухэлементной классический ударной системы [5]. Как показали результаты расчета? выполняется условие применимости этих уравнений

$$
t_{m} \geq 3 T,
$$

где $t_{m}$ - время удара, $t_{m}=0,6-1,4$ мс; $T$ - период собственных колебаний ударника и бойка, $T=0,13$ мс.

Исходя из выводов [5] о существующих видах нагрузочных характеристик разрушения, с учетом наших наблюдений за процессом удара, предполагали, что внедрение ударника в породу в условиях эксперимента характеризуется тремя основными стадиями:

- упругой деформацией породы до достижения на площади ее контакта с ударником напряжения $\sigma_{\kappa}$, при котором происходит взрывоподобное разрушение породы под площадкой контакта;

- продвижением ударника через ядро разрушения породы с вытеснением части продуктов из лунки и прессованием оставшихся продуктов без достижения дна зоны разрушения;

- отбрасыванием ударника силами остаточной упругости спрессованных продуктов разрушения.

Зависимость силы сопротивления породы $N$ от деформации $\alpha$ (рис.4) для этого случая соответствует нагрузочной характеристике типа $V$ [5] и состоит из трех силовых функций: нагрузки $N_{1}$ при упругом деформировании породы под площадкой контакта, нагрузки $N_{2}$ при внедрении ударника в продукты разрушения породы и разгрузки $N_{3}$, каждая из которых характеризуется своей жесткостью $\left(g_{1}, g_{2}, g_{3}\right)$. При этом функции $N_{1}, N_{2}, N_{3}$, как и для внедрения тела с постоянной площадью контакта, имеют линейный характер. Площадь фигуры на рис.4 - работа нагружения $A_{\mathrm{H}}$, заштрихованная площадь - работа $A_{\mathrm{p}}$, затраченная на разрушение.

Максимальные сила сопротивления породы $N_{m}$ и внедрение $\alpha_{\text {вн }}$, а также время удара $t_{m}$ для такой нагрузочной характеристики [5]:

$$
\begin{gathered}
N_{m}=N_{\mathrm{p}} \sqrt{1-\frac{g_{2}}{g_{1}}+\frac{2 A_{\mathrm{H}} g_{2}}{N_{\mathrm{p}}^{2}}} ; \\
\alpha_{\mathrm{BH}}=\alpha_{m}-\frac{N_{m}}{g_{3}}=N_{\mathrm{p}}\left(\frac{1}{g_{2}}-\frac{1}{g_{1}}\right)\left(\sqrt{1-\frac{g_{2}}{g_{1}}}+\frac{2 A_{\mathrm{H}} g_{2}}{N_{\mathrm{p}}^{2}}-1\right) ; \\
t_{m}=\sqrt{\frac{M}{g_{2}}} \operatorname{arctg} \sqrt{\frac{2 A_{\mathrm{H}} g_{2}}{N_{\mathrm{p}}^{2}}},
\end{gathered}
$$

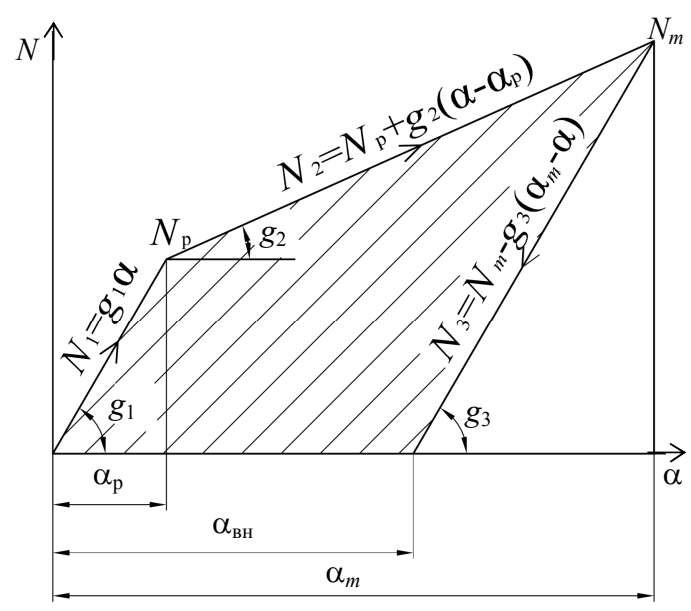

Рис.4. Вид нагрузочной характеристики системы, принимаемой при расчетах параметров удара где $M$ - масса падающего объекта; $N_{\mathrm{p}}$ - усилие контактного разрушения породы,

$$
N_{\mathrm{p}}=f_{\mathrm{K}} \sigma_{\mathrm{\kappa p}},
$$

$f_{\mathrm{K}}=\pi d^{2} / 4-$ площадь контакта; $\sigma_{\text {кр }}-$ напряжение в месте контакта, при котором возникающие при ударе растягивающие и сдвиговые напряжения $\sigma_{\mathrm{p}}$ в породе приводят к ее взрывоподобному разрушению под площадкой контакта.

Допущения, принятые при расчетах:

- за значение критического контактного напря-

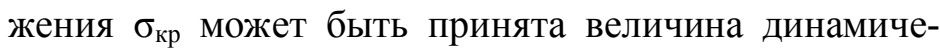
ской твердости породы (для гранита 1305 МПа [9]); 
- для установления контактной жесткости системы $g_{1}$, как и для круговой площадки контакта диаметром $d$, справедлива формула из [5]:

$$
g_{1}=\frac{2 E_{\Pi} d}{3\left(1-\mu_{\Pi}^{2}\right)},
$$

при модуле упругости $E_{\text {п }}=50$ ГПа и коэффициенте Пуансона $\mu_{\text {п }}=0,2$ гранита [5];

- по аналогии с соотношением жесткостей $g_{2} / g_{1}$ и $g_{3} / g_{1}$, которое можно установить из анализа приведенных в работе [6] экспериментальных силовых характеристик контактного разрушения хрупких горных пород, за жесткость $g_{2}$ в нашем случае может быть принята величина, равная $0,16 g_{1}$, а за $g_{3}$ - величина $g_{1}$;

- только около половины кинетической энергии $A_{0}$ ударника затрачивается на упругую деформацию и разрушение породы (для гранита 58,6 \% [5]), остальная энергия затрачивается на тепловые потери в окружающую среду, упругую и пластическую деформацию ударника, а также износ его контактной поверхности [9]), вследствие чего принимали $A_{\mathrm{H}}=0,586, A_{0}=0,68$ Дж.

На рис.5 представлены значения времени удара $t_{m}$ (кривая 1), максимальных силы сопротивления породы $N_{m}$ (кривая 2), контактного напряжения $\sigma_{\text {к }}=N_{m} / \pi d^{2} / 4$ (кривая 3) и внедрения $\alpha_{\text {вн }}$

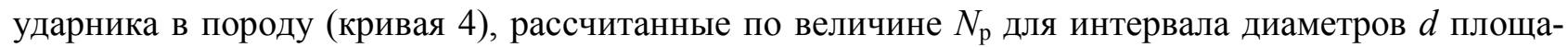
док контакта, имеющего место в экспериментах (площадок притупления). На рис.5 для соответствующих значений $d$ приведены значения глубин $h$ лунок, установленные экспериментально (см. рис.2, б).

Как видно из графика на рис.5, при постоянном импульсе силы $M v_{0}=N_{m} t_{m}$ с увеличением диаметра $d$ контактной площади (площадки притупления ударника) максимальная сила сопротивления породы $N_{m}$ монотонно возрастает, а время удара $t_{m}$, максимальное контактное напря-

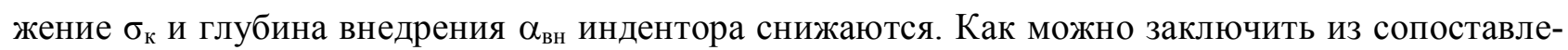
ния местоположения экспериментальных точек и кривой 4, линия регрессии зависимости $\alpha_{\text {вн }}=f(d)$ показывает удовлетворительную сходимость с экспериментальными данными для всех сталей.

Полученная удовлетворительная сходимость результатов расчета и эксперимента может служить подтверждением предлагаемой математической модели и правомочности принятых допущений.

Закономерности разрушения материала ударника. Установленные величины $K$ и $I$, pacположенные в порядке возрастания износостойкости ударников из анализируемых марок сталей, а также определенные экспериментальным путем значения твердости HV и рассчитанные [12] по ним пределы текучести $\sigma_{\mathrm{T}}$ и прочности $\sigma_{\mathrm{B}}$ сталей для условий статического растяжения образцов представлены в табл.1. Там же приведены значения числа ударов $n^{*}, n^{* *}$, при которых для ударника из каждой стали наблюдается переход к последующей стадии взаимодействия, соответствующие им диаметры $d^{*}, d^{* *}$ площадки притупления, напряжения $\sigma_{\kappa}^{*}, \sigma_{\kappa}^{* *}$ на площадке контакта ударника с породой из кривой 3 (рис.5) для $d^{*}, d^{* *}$.

Как следует из данных табл.1, установленная ударно-абразивная износостойкость сталей соотносится, в целом, с их твердостью и величиной прочностных показателей $\sigma_{\mathrm{B}}, \sigma_{\mathrm{T}}$, возрастая с увеличением этих параметров. При этом наименьшая износостойкость наблюдается для стали $38 \mathrm{XM} \mathrm{после} \mathrm{типовой} \mathrm{термической} \mathrm{обработки,} \mathrm{наивысшая,} \mathrm{в} \mathrm{2,7} \mathrm{раза} \mathrm{большая} \mathrm{-} \mathrm{для} \mathrm{стали} \mathrm{Х12МФ}$ после обработки холодом. Можно отметить, что обработка холодом приводит к повышению износостойкости и всех других сталей (от 11 до 26 \%). 
Ударно-абразивная износостойкость исследованных материалов ударника в сопоставлении с их прочностными характеристиками и критическими параметрами взаимодействия ударника и породы

\begin{tabular}{|c|c|c|c|c|c|c|c|c|c|c|c|}
\hline $\begin{array}{c}\text { Марка стали } \\
\text { ударника }\end{array}$ & $K$, мг/удар & $I$, удар/мг & $\mathrm{HV}$ & $\sigma_{\mathrm{B}}, \mathrm{MПа}$ & $\sigma_{\mathrm{T}}, \mathrm{MПа}$ & $n^{*}$ & $n^{* *}$ & $d^{*}, \mathrm{MM}$ & $d^{* *}, \mathrm{MM}$ & $\sigma_{\mathrm{k}}{ }^{*}, \mathrm{MПа}$ & $\sigma_{\mathrm{\kappa}}^{* *}, \mathrm{M \Pi а}$ \\
\hline $38 \mathrm{XM}$ & 0,0027 & 370 & 529 & 1933 & 1478 & 10 & $\sim 5100$ & 1,011 & 2,114 & 3643 & 1651 \\
\hline $38 \mathrm{XM}_{x}$ & 0,0023 & 435 & 536 & 1953 & 1529 & 10 & $\sim 5400$ & 0,986 & 2,047 & 3767 & 1691 \\
\hline У8 & 0,0019 & 526 & 707 & 2540 & 1943 & 8 & $\sim 3600$ & 0,889 & 1,763 & 4340 & 1915 \\
\hline $\mathrm{y} 8_{x}$ & 0,0017 & 588 & 717 & 2577 & 1971 & 8 & $\sim 3900$ & 0,876 & 1,724 & 4435 & 1955 \\
\hline $\mathrm{X} 12 \mathrm{M} \Phi$ & 0,0013 & 741 & 694 & 2492 & 1905 & 8 & $\sim 4100$ & 0,866 & 1,680 & 4502 & 2003 \\
\hline $\mathrm{X} 12 \mathrm{M} \Phi_{x}$ & 0,0010 & 1000 & 708 & 2544 & 1946 & 8 & $\sim 4900$ & 0,836 & 1,620 & 4729 & 2076 \\
\hline
\end{tabular}

Видно, что по мере возрастания прочности и износостойкости сталей величины контактного напряжения $\sigma_{\kappa}^{* *}, \sigma_{\kappa}^{*}$, соответствующие переходу от стадии к стадии взаимодействия, возрастают. При этом между значениями $\sigma_{\kappa}^{*}$ и $\sigma_{\mathrm{B}}$, а также $\sigma_{\kappa}^{* *}$ и $\sigma_{\mathrm{T}}$ существует определенная корреляция: первые $\left(\sigma_{\kappa}^{*}, \sigma_{\kappa}^{* *}\right)$ примерно в одинаковое количество раз больше вторых. Из фактов наличия трех характерных стадий взаимодействия (см. рис.3) и существования указанной пропорции для всех сталей можно предположить, что установленные расчетно-экспериментальным путем критические значения $\sigma_{\kappa}^{*}, \sigma_{\kappa}^{* *}$ контактного напряжения соответствуют напряжению в прилегающем к площадке контакта слое данного материала ударника, начиная с которого он способен в динамических условиях разрушаться $\sigma_{\kappa}^{*}$ или пластически деформироваться $\sigma_{\kappa}^{* *}$. Для условий статического растяжения образцов аналогом напряжения $\sigma_{\kappa}^{*}$ является параметр «истинное разрушающее напряжение $S_{\mathrm{K}}$ », а напряжения $\sigma_{\mathrm{K}}^{* *}-$ предел текучести $\sigma_{\mathrm{T}}$ материала со значениями меньшими, чем соответственные динамические характеристики сталей. Можно отметить, что примерно такое же превышение значений предела текучести $\sigma_{\mathrm{T}}$ (до 1,1 раза) и предела прочности $\sigma_{\text {в }}$ (до 2 раз), установленных при высоких скоростях деформации, над установленными при статическом сжатии и растяжении образцов, описано в работах $[2,6]$ для технического железа и среднеуглеродистой легированной стали.

При малых диаметрах площадки притупления $\left(n<n^{*}, d<d^{*}\right.$, стадия I) развиваемые при уда-

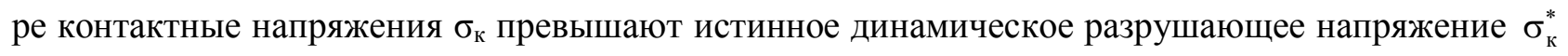
данной стали и на площадке контакта возникают трещины, развитие которых приводит к выкрашиванию значительных объемов металла, что регистрируется в виде заметной убыли массы ударника. При больших диаметрах $\left(d^{*}<d \leq d^{* *}, n^{*}<n \leq n^{* *}\right.$, стадия II) возникающих напряжений не хватает для разрушения материала ударника, но оказывается достаточно для его пластической деформации, сопровождаемой перемещением металла с центральной части площадки контакта на периферийную. Исходя из факта наличия заметной убыли массы ударника на этой стадии, можно заключить, что значительная часть деформированного и ослабленного трещинами объема металла уносится движущимися продуктами разрушения породы.

Такой вывод о разрушении и значительной пластической деформации острия ударника на первых стадиях взаимодействия подкрепляется результатами специально проведенных авторами испытаний, при которых удары ударником наносили не по абразиву, а по гладкой пластине из более твердого материала, не подвергаемого разрушению. Как можно заключить из результатов этого эксперимента, представленных на рис.6, при малом числе ударов имеет место откалывание частей острия ударника с появлением на площадке контакта волн деформированного металла, направленных от центра к периферии. На рис.6 видно проявление краевого эффекта - выкрашивания периферийных участков площадки контакта.

Чем больше число ударов $n$ на первых стадиях взаимодействия и больше площадка притуп-

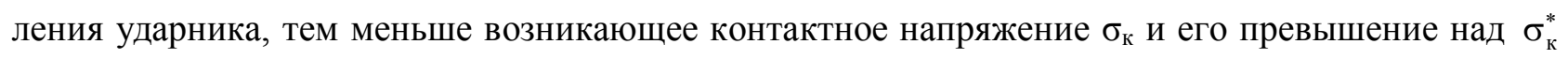
или $\sigma_{\kappa}^{* *}$ использованной стали, и, соответственно, тоньше зона металла на площадке контакта, 
$a$

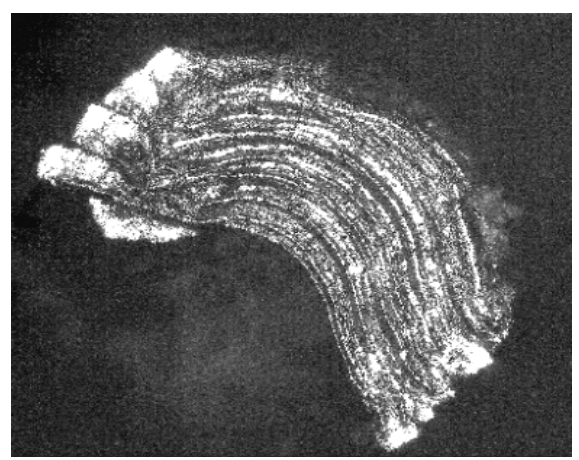

6

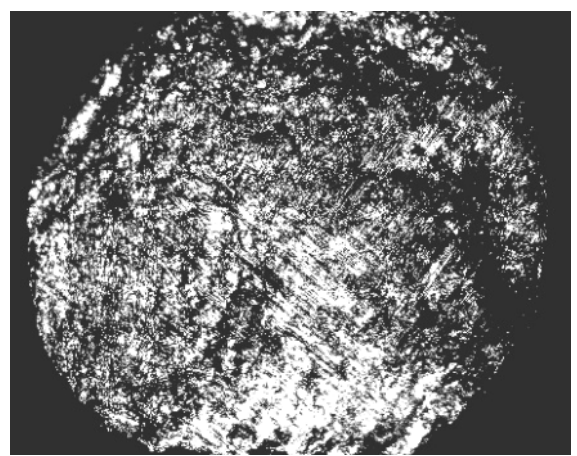

Рис.6. Вид площадки притупления ударника из стали У8 после удара о твердую металлическую подложку на стадии I взаимодействия $(a)$ и гранит на стадии III (б)

подвергаемого разрушению или деформации и, следовательно, меньше величина $\Delta m$. При $n \geq n^{* *}$, $d \geq d^{* *}$ (стадия III), возникающие контактные напряжения $\sigma_{\mathrm{\kappa}}$ не достигают уровня $\sigma_{\kappa}^{* *}$ и острие ударника не подвергается пластической деформации. Появление на этой площадке параллельных царапин при переходе к удару по породе свидетельствует о том, что в этом случае металл площадки подвергается воздействию движущихся абразивных частиц. Результатом царапания является существенно меньшая, по сравнению со стадиями I, II, убыль массы металла, величина которой определяется абразивной износостойкостью использованной для изготовления ударника стали, зависящей от ее твердости и особенностей структуры [3]. Необходимо отметить, что наличие на площадке контакта, наряду с царапинами, лунок может свидетельствовать о том, что кроме изнашивания движущимися частицами абразива материал ударника при ударе подвергается и внедрению в него неподвижных абразивных частиц [2], что имеет место на стадии уплотнения остающихся в лунке продуктов разрушения породы.

Долю энергии, затрачиваемую при разрушении породы на изнашивание ударника на установившейся (третьей) стадии его износа, оценивали, исходя из установленных скоростей изнашивания материалов $K$ и критических напряжений $\sigma_{\kappa}^{*}$ соответствующих сталей. При этом предполагали, что, поскольку в нашем случае износ материала происходит преимущественно за счет

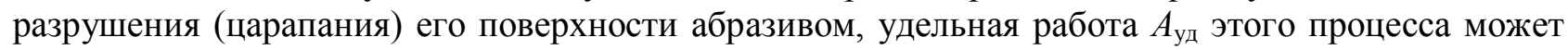
быть оценена по формуле, предложенной в работе [1] для разрушения металлов при растяжении образцов

$$
A_{\mathrm{yд}}=\frac{S_{\mathrm{K}}}{\rho},
$$

где $S_{\kappa}$ - истинное разрушающее напряжение металла, в соответствии с приведенными предположениями авторов, для динамических условий равно $\sigma_{\kappa}^{*}$ конкретной стали из табл. $1 ; \rho-$ плотность, $\rho=7,8510^{3}$ кг $/ \mathrm{M}^{3}$ для всех сталей.

Тогда работа, затраченная на изнашивание материала ударника за удар,

$$
A_{\mathrm{Me}}=K A_{\text {уд }}=\frac{K \sigma_{\mathrm{K}}^{*}}{\rho},
$$

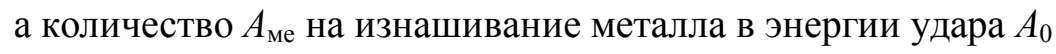

$$
A_{\mathrm{Me} \%}=\frac{A_{\mathrm{me}}}{A_{0}} \frac{K \sigma_{\mathrm{K}}^{*}}{A_{0} \rho} .
$$

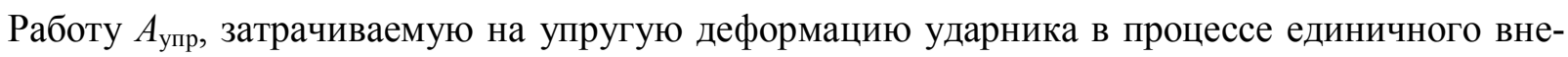
дрения в гранит на установившейся стадии взаимодействия III, рассчитывали как произведение максимальной силы сопротивления породы $N_{m}$ для $d=d^{* *}$ на суммарное уменьшение длин $\Delta l_{\text {гупр }}$

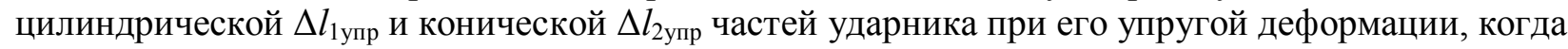

$$
\Delta l_{1 \text { упр }}=\frac{N_{m} l_{1}}{S_{1} E},
$$


где $S_{1}$ - площадь сечения цилиндрической части; $E$ - модуль Юнга, $E=200 \cdot 10^{9}$ МПа для всех сталей.

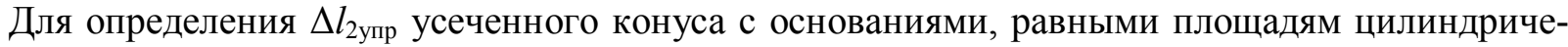
ской части ударника и площадки притупления, переменную по высоте площадь его поперечного сечения $S_{i}$ выражали через расстояние $x$ от вершины конуса и угол заострения $\beta=30^{\circ}$

$$
S_{i}=\pi x^{2} \operatorname{tg}^{2} \frac{\beta}{2}
$$

и решали дифференциальное уравнение относительного изменения высоты конуса за счет упругой деформации как функции от $x$

$$
\frac{d l}{d x}=\frac{\sigma}{E}=\frac{N_{m}}{E \pi x^{2} \operatorname{tg} \frac{\beta}{2}}
$$

которое интегрировали по текущей координате $x$ от вершины конуса до площадки притупления $x_{l}\left(\Delta l\right.$ при $\left.d^{* *}\right)$ и до основания $x_{2}\left(l_{2}\right)$, в результате чего конечное уравнение имело вид

$$
\Delta l_{2 \text { yпр }}=\frac{N_{m}}{E \pi \operatorname{tg}^{2} \frac{\beta}{2}} \int_{x_{1}}^{x_{2}} \frac{1}{x^{2}} d x=-\frac{N_{m}}{E \pi \operatorname{tg}^{2} \frac{\beta}{2}} \frac{1}{x} \frac{x_{2}}{x_{1}}=\frac{N_{m}}{E \pi \operatorname{tg} \frac{\beta}{2}}\left(\frac{1}{x_{1}}-\frac{1}{x_{2}}\right) .
$$

Соответственно, величина $A_{\text {упр\% }}$ равна $A_{\text {упр }} / A_{0}$.

В предположении, что установленные скорости ударно-абразивного изнашивания сталей $K$ из табл.2 сохраняются при дальнейших ударах вплоть до диаметра 3,55 мм, при котором прекращается образование лунки, рассчитывали число ударов $n^{* * *}$ и получаемую суммарную глубину лунок $h_{\Sigma}$ к этому моменту для ударника из каждой стали.

Таблица 2

\begin{tabular}{|c|c|c|c|c|c|c|c|}
\hline Марка стали & $A_{\text {уд }}$, Дж/мг & $A_{\mathrm{мe}}$, Дж & $A_{\text {ме }}, \%$ & $A_{\text {упр, }}$, Дж & $A_{\text {упр }}, \%$ & $n^{* * *}$ & $h_{\Sigma}, \mathrm{MM}$ \\
\hline 38XM & 0,464 & 0,0013 & 0,108 & 0,114 & 9,8 & $\sim 68500$ & 3410 \\
\hline $38 \mathrm{XM}_{x}$ & 0,480 & 0,0011 & 0,095 & 0,107 & 9,3 & $\sim 79900$ & 4219 \\
\hline y8 & 0,553 & 0,0011 & 0,091 & 0,085 & 7,3 & $\sim 93800$ & 6352 \\
\hline $\mathrm{y} 8_{x}$ & 0,565 & 0,0010 & 0,083 & 0,082 & 7,1 & $\sim 104700$ & 7376 \\
\hline Х12MФ & 0,574 & 0,0008 & 0,067 & 0,080 & 6,9 & $\sim 131000$ & 9569 \\
\hline $\mathrm{X} 12 \mathrm{M} \Phi_{x}$ & 0,602 & 0,0006 & 0,052 & 0,076 & 6,6 & $\sim 176200$ & 13623 \\
\hline
\end{tabular}

Энергетические параметры процесса ударно-абразивного изнашивания и упругой деформации ударника из различных марок сталей

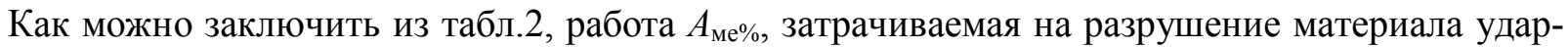
ника в процессе единичного внедрения в гранит, составляет $\sim 0,1 \%$ от энергии удара. При этом с увеличением износостойкости использованной для изготовления ударника стали доля работы

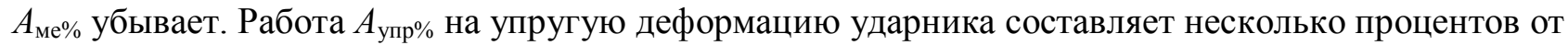

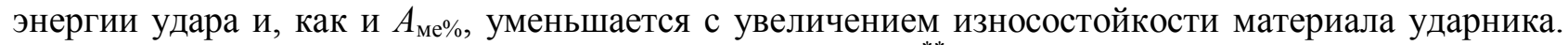
Так, если для наименее прочной стали $38 \mathrm{XM} \mathrm{это} 9,8 \%\left(d^{* *}=2,11 \mathrm{MM}, N_{m}=5,80 \mathrm{\kappa H}, \Delta l_{1 \text { упр }}=0,0182\right.$

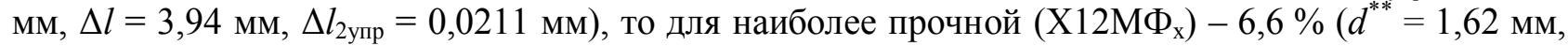
$N_{m}=4,28 \mathrm{\kappa H}, \Delta l_{1 \text { упр }}=0,0127 \mathrm{мм}, \Delta l=3,02 \mathrm{мм}, \Delta l_{2 \text { упр }}=0,0229$ мм). Как показывают расчеты, при дальнейшем увеличении числа ударов (сверх $\left.n^{* *}\right)$ и соответственном увеличении диаметра пло-

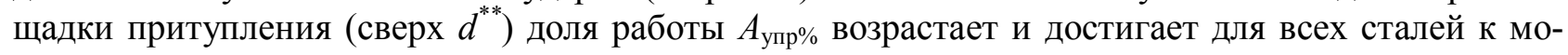
менту полного притупления острия ударника величины $~ 36 \%$.

Из табл. 2 следует, что к моменту прекращения внедрения ударника в породу суммарная глубина лунок $h_{\Sigma}$, выбитых ударником из стали Х $12 \mathrm{M} \Phi_{x}$ после обработки холодом, в четыре раза превышает аналогичный показатель для ударника из стали $38 \mathrm{XM}$ из-за существенно большей износостойкости ударника из стали $\mathrm{X} 12 \mathrm{M} \Phi_{x}$. 
Заключение. Таким образом, как показали расчеты и эксперименты, процесс изнашивания конусообразного стального ударника при его единичных ударах по граниту характеризуется существованием трех стадий взаимодействия, каждая из которых определяется соотношением прочностных характеристик $\sigma^{*}, \sigma^{* *}$, демонстрируемых материалом ударника в динамических условиях, с величиной напряжения $\sigma_{\kappa}$, возникающего на площадке контакта ударника с породой и снижающегося по мере увеличения числа ударов $n$. На последней установившейся стадии взаимодействия убыль массы ударника с увеличением числа ударов практически не изменяется и определяется износостойкостью использованной стали, вследствие чего число ударов до полного притупления острия ударника и получаемая суммарная глубина лунок для анализируемых сталей различаются в 2,6 и 4,0 раз соответственно.

Благодарность. Авторы выражают глубокую признательность доценту А.П.Баталову за помощь, оказанную при подготовке данной статьи.

\section{ЛИТЕРАТУРА}

1. Болобов В.И. К вопросу о разогреве фрагментов разрушения конструкций // Металловедение и термическая обработка металлов. 2010. № 2. С. 44-45

2. Виноградов В.Н. Изнашивание при ударе / В.Н.Виноградов, Г.М.Сорокин, А.Ю.Албагачиев. М.: Машиностроение. 1982. $192 \mathrm{c}$

3. Ле Тхань Бинь. Влияние обработки холодом на механические свойства и износостойкость материалов пик гидромолотов / Ле Тхань Бинь, В.И.Болобов, Нгуен Кхак Линь // Горный информационно-аналитический бюллетень. 2017. № 12 (специальный выпуск 25). 12 с.

4. Обработка холодом как способ повышения износостойкости материала бурового инструмента / Ле Тхань Бинь, В.И.Болобов, Г.А.Юсупов, М.П.Мосеев // Горный информационно-аналитический бюллетень. 2016. № 11. С. 108-114.

5. Соколинский В.Б. Машины ударного разрушения. М.: Машиностроение. 1982. 185 с.

6. Третьяков А.B. Механические свойства металлов и сплавов при обработке давлением / А.В.Третьяков, В.И.Зюзин. М.: Металлургия. 1973. 224 с.

7. Ушаков Л.С. Гидравлические машины ударного действия / Л.С.Ушаков, Ю.Е.Котылев, В.А.Кравченко. М.: Машиностроение. 2000. $416 \mathrm{c}$.

8. Холод в машиностроении / А.П.Клименко, Н.В.Новиков, Б.Л.Смоленский, В.И.Могильный, В.И.Климентьев, М.А.Рохленко. М.: Машиностроение. 1969. 248 с.

9. Шелковников И.Г. Использование энергии удара в процессах бурения. М.: Недра, 1977. 160 с.

10. Candane D. Effect of Cryogenic Treatment on Microstructure and Wear Characteristics of AISI M35 HSS / D.Candane, N.Alagumurthi, K.Palaniradja // International Journal of Materials Science and Applications. 2013. Vol. 2. P. 56-65

11. Metallurgical Principles of Cryogenically Treated Tool Steels - a Review on the Current State of Science / S.S.Gill, J.Singh, R.Singh, H.Singh // International Journal of Advanced Manufacturing Technology. 2010. Vol. 54. P. 59-82.

12. Pavlina E.J. Correlation of Yield Strength and Tensile Strength With Hardness for Steels / E.J.Pavlina, C.J.Van-Tyne // Journal of Materials Engineering and Performance. 2008. Vol. 17(6). P. 888-893

13. Tated R.G. Improvement in Tool Life of Cutting Tool by Application of Deep Cryogenic Treatment / R.G.Tated, S.R.Kajale, Iyer Kumar // 7th International Tooling Conference Held / Politecnico di Torino, Italy, 2006. P. 135-141.

Авторы: Болобов В.И., д-р техн. наук, профессор, boloboff@таil.rи (Санкт-Петербургский горный университет, Санкт-Петербург, Россия), Ле Тхань Бинь, аспирант (Санкт-Петербургский горный университет, Санкт-Петербург, Россия).

Статья поступила в редакиию 10.01.2018.

Статья принята к публикачии 25.05.2018. 